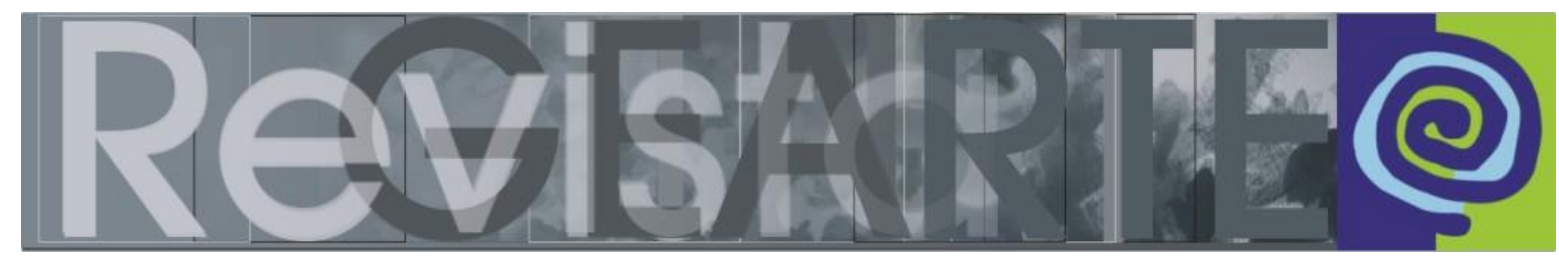

Volume 1, Número 1, Abril/2014, ISSN 2357-9854

\title{
A pesquisa no campo da arte-educação visual e o ensino da arte na educação básica
}

\author{
Maria Helena Wagner Rossi (UCS - Brasil)
}

\section{RESUMO}

O texto tem o objetivo de refletir sobre o tema "A pós-graduação e suas interlocuções com a educação básica. Para tal, situa as reflexões num contexto mais amplo, considerando o papel da educação básica na superação do subdesenvolvimento do país, abordando brevemente as relações entre desenvolvimento, cultura e educação, para, então, enfocar o campo da arte-educação visual em algumas dimensões, tais como: a disciplina Arte na educação básica, os cursos de formação de professores e o contexto da pesquisa no campo da arte-educação visual nos cursos de pós-graduação em educação. Sem a pretensão de dar respostas ou apontar soluções, o texto se propõe a formular perguntas, visando provocar novas reflexões.

\section{PALAVRAS-CHAVE}

arte-educação; educação básica; pós-graduação

\section{ABSTRACT}

The text aims to reflect on the theme "The postgraduate education and its dialogues with basic education.For such, it points the reflections in a wider context, considering the role of basic education within the overcoming of the country's underdevelopment, briefly approaching the relations between development, culture and education, to achieve the field of visual art education in some dimensions such as: the discipline Arts in school, training courses for teachers and the context of research in the field of visual art education in postgraduate education. Without attempting to provide answers or point solutions, the text proposes to formulate questions, in order to elicit new reflections.

\section{KEYWORDS}

art education; basic education; postgraduate education

Fazer perguntas talvez seja um modo de orientar nossos olhares para "ver o que ainda não vimos". Talvez seja um passo necessário para elaborar nossa linguagem para "dizer o que ainda não foi dito" (FLEURI, 2001, p. 117).

Concordando com Fleuri quando diz que "fazer perguntas talvez seja um modo de orientar nossos olhares para 'ver o que ainda não vimos'”, este texto ${ }^{1}$ não tem respostas ou soluções para diminuir o discutido distanciamento entre a pós-graduação e a educação básica no Brasil, limitando-se a trazer perguntas e reflexões: como relacionar a formação do professor de Arte, a pesquisa relacionada à arte-educação

\footnotetext{
1 Texto produzido originalmente para a palestra da Sessão Especial do GT Educação e Arte na IX edição da ANPEDSUL realizada em Caxias do Sul (UCS) em julho de 2012, que teve como tema central: A Pós-Graduação e suas interlocuções com a Educação Básica.
} 
visual em cursos stricto sensu, a sala de aula de Arte na educação básica e os índices de desenvolvimento?

\section{Desenvolvimento, cultura, educação}

Há controvérsias no momento de classificar o Brasil quanto ao seu nível de desenvolvimento. Embora nas classificações oficiais sejamos um país "em desenvolvimento", nas palavras de Marcio Pochmann, presidente do Ipea (Instituto de Pesquisa Econômica Aplicada), "o Brasil ainda é um país subdesenvolvido, infelizmente. E esse subdesenvolvimento não expressa apenas a desigualdade de renda, mas também a forma como a classe trabalhadora é inserida no mercado de trabalho" (POCHMANN, 2012, p. 14). Na mesma linha, Fellet, baseado no Relatório de Desenvolvimento do PNUD (Programa das Nações Unidas para 0 Desenvolvimento) de 2011, aponta que "embora o Brasil tenha aumentado ligeiramente seu Índice de Desenvolvimento Humano ${ }^{2}$ (IDH) neste ano e subido uma posição no ranking global do indicador, o país mostrou resultados piores quando considerada a desigualdade social e a de gênero" (FELLET, 2011).

Vale lembrar que o Chile ocupa o 44ํl lugar e a Argentina, o 45ํㅡo IDH de 2011, o que os coloca no patamar de desenvolvimento muito alto. O Brasil, com índice geral de 0,718, está no 84ํlugar, com índice de desenvolvimento alto. Por ser um país grande e heterogêneo, talvez os desafios sejam maiores do que os dos vizinhos da América do Sul, mas parece uma incongruência o fato de o país ser respeitado em muitos aspectos da arte e da cultura e, ao mesmo tempo, ocupar um lugar mediano no ranking do desenvolvimento humano. Mediano, pois quando entra o critério da igualdade social, o índice cai para 0,519, compatível com IDH baixo.

Na questão de ser ou não ser desenvolvido, a educação é um fator decisivo. Várias organizações internacionais ${ }^{3}$ mostram, periodicamente, relatórios estatísticos sobre o desenvolvimento dos países, sendo que os sistemas educacionais são um

\footnotetext{
${ }^{2} \mathrm{O}$ IDH avalia os fatores: conhecimento, vida longa e saudável e padrão de vida, através da avaliação da educação (anos médios de estudos), da longevidade (expectativa de vida da população) e do Produto Interno Bruto per capita dos países.

3 Por exemplo: Nações Unidas (NU), Banco Mundial, OCDE (Organização para Cooperação e Desenvolvimento Econômico), UNESCO (Organização para a Educação, a Ciência e a Cultura das Nações Unidas), PNUD (Programa das Nações Unidas para o Desenvolvimento), etc.
} 
elemento decisivo na constituição desses relatórios. Tais documentos têm influenciado a formulação de políticas públicas nacionais.

O desenvolvimento do Brasil vem sendo abordado por diversos ângulos, mas aqui interessam as abordagens que consideram a importância da cultura no desenvolvimento. O ex-ministro da Cultura João Luiz Silva Ferreira ${ }^{4}$ (2008-2010) defende o investimento em educação e cultura visando ao desenvolvimento:

\begin{abstract}
O Brasil não vai se tornar uma grande nação realizando o crescimento da economia e colocando um pouco mais de dinheiro no bolso das pessoas. Isso é pouco. É fundamental, mas é pouco. É preciso garantir educação de qualidade para todos e garantir acesso pleno à cultura. Os números vocês devem conhecer porque eu repetia exaustivamente e não me esqueci. Pouco mais de $5 \%$ dos brasileiros entraram mais de uma vez em um museu, só $13 \%$ dos brasileiros vão ao cinema, só 17\% compram livros, a média de leitura de livros é 1,7 per capita. Estão mudando o critério para ver se aumenta o número, mas isso não é bom fazer. Faziam na época da ditadura essas mágicas estatísticas (FERREIRA, 2012).
\end{abstract}

Nas discussões sobre o desenvolvimento socioeconômico, há uma miríade de fatores que poderiam (ou deveriam) ser considerados, desde novos conceitos, como o de "economia criativa", até a sala de aula de $\operatorname{Arte}^{5}$ na educação básica. O que se quer frisar, aqui, é a pertinência de defender um conceito ampliado de desenvolvimento ${ }^{6}$, onde caiba a arte e a cultura.

A cultura brasileira é rica e heterogênea; a arte contemporânea brasileira (erudita e popular) é respeitada e valorizada internacionalmente; a Bienal de São Paulo é uma das duas mais importantes do mundo. Mas o acesso da população a esse patrimônio não está acontecendo, o que gera a baixa classificação do Brasil no ranking do desenvolvimento. A distribuição do capital cultural de uma nação é um dos fatores que determinam sua riqueza de conhecimento. Um país desenvolvido é um país rico em conhecimento. Desenvolvimento pressupõe diálogos interculturais e não um apartheid cultural como temos no Brasil. Sobre essa condição brasileira, diz Barbosa:

Para o povo o candomblé, o carnaval, o bumba-meu-boi e a sonegação de códigos eruditos de arte que presidem o gosto da classe dominante, que, por

\footnotetext{
${ }^{4}$ Conhecido como Juca Ferreira, em entrevista à Folha de São Paulo no dia 22/03/2012.

${ }^{5}$ Neste texto, o termo quando grafado com inicial maiúscula se refere à disciplina ou componente curricular da educação básica.

${ }_{6}^{6}$ Pode-se saber mais sobre o IDH em http://hdr.undp.org/en/media/FAQs_2011_HDI_ES.pdf. Human Development Report (ONU)
} 
ser dominante, tem possibilidade de ser mais abrangente e também dominar os códigos da cultura popular. [Mas] as massas têm direito à sua própria cultura e também à cultura da elite, da mesma maneira que a elite já se apropriou da cultura da massa, embora quase sempre hospedada no Hilton Hotel (BARBOSA, 1991, p. 33).

O que a educação pode fazer para minimizar o apartheid cultural? Alcione Araújo diz que a educação se afastou da cultura. Os motivos são vários, dentre os quais estão a ênfase nas tecnologias e a busca pela profissionalização. Diz o escritor que a educação, em sua trajetória recente, renunciou às artes, à cultura e ao pensamento (2007). Nesse contexto, o papel da arte na escola tem que ser discutido; o nosso papel como arte-educadores, mesmo que "microscópico", tem que ser entendido num contexto mais amplo. O processo é histórico e a educação não é a responsável pelas diferenças, mas pode fazer diferença. $O$ último relatório da OCDE confirma essa ideia: "O Brasil não tem uma história de discriminação legal com base na raça ou etnia, mas tem sérias dificuldades em termos de equidade no acesso à riqueza e educação" (OCDE, 2010, p. 30).

Os programas de avaliação da educação básica brasileira utilizam diferentes sistemas nos diversos níveis de escolarização, tais como: Provinha Brasil, ENEM, ENCCEJA, Prova Brasil. Além disso, a cada três anos os alunos são avaliados nas áreas de Linguagem, Matemática e Ciências por meio do Pisa (Programa Internacional de Avaliação de Alunos) $)^{7}$. O Pisa avalia o desempenho de alunos de 15 anos, "não somente quanto ao domínio curricular, mas também quanto aos conhecimentos relevantes e às habilidades necessárias à vida adulta" (BRASIL, 2008, p. 6).

As avaliações mostram que o desempenho da maioria dos alunos da rede pública é baixo (BRASIL, 2008, p. 14). O PDE (Plano de Desenvolvimento da Educação) reconhece que "este é um fato já amplamente conhecido mostrando que o desempenho do aluno reflete, ainda que de forma não determinística, o capital cultural de sua família, que, no Brasil, está muito associado ao NSE [nível socioeconômico]" (BRASIL, 2008, p. 15). As teorias reprodutivistas já explicitaram o processo pelo qual o capital cultural retorna às mãos do capital cultural, reproduzindo a estrutura de sua distribuição entre as classes sociais (BOURDIEU, 1982, p. 297). Assim, caberia a

\footnotetext{
${ }^{7}$ O Brasil é um dos países convidados pela OCDE para participar do Pisa, que foi desenvolvido pelos países participantes dessa Organização.
} 
pergunta: que caminhos a arte-educação deveria seguir nesse contexto? Os currículos deveriam ser iguais, mesmo considerando as diferenças entre escola pública e particular? É ético defender a igualdade em contextos a priori desiguais?

\title{
Educação e qualidade
}

Em fevereiro último, a OCDE pediu a seus países-membros que façam investimentos em educação, como saída para a crise econômica. A Organização salienta que um ponto-chave nessa luta é "atrair, assessorar e conservar professores de alta qualidade":

\begin{abstract}
As políticas devem aumentar a qualidade dos professores para as escolas e alunos desfavorecidos, através dos seguintes meios: fornecimento de formação específica para professores, com vista a permitir que os professores recebam as competências e os conhecimentos de que necessitam para trabalhar em escolas com alunos desfavorecidos; fornecimento de programas de orientação para professores principiantes; desenvolvimento de condições de trabalho positivas, com vista a melhorar a eficácia dos professores e a aumentar a conservação dos mesmos; e desenvolver incentivos financeiros e profissionais adequados, com vista a atrair e conservar professores de qualidade em escolas desfavorecidas (OCDE, 2012, p. 4).
\end{abstract}

Considerando as recomendações da OCDE, um pergunta que se pode fazer é: como um país com modestos índices de desenvolvimento pode "atrair, assessorar e conservar professores de alta qualidade"? Para pensar sobre isso, trago alguns dados sobre a renumeração do trabalho docente na educação básica brasileira em 2012. No Distrito Federal um professor com $40 \mathrm{~h}$ de trabalho semanal recebia $\mathrm{R} \$ 2.315,00$; em Roraima, que tinha o segundo maior piso do país, esse professor recebia $R \$ 2.142,00$. Na Região Sul, no Paraná, o piso era de $R \$ 1.224,00$; em Santa Catarina $R \$ 1.504,00$ e no Rio Grande do Sul o professor recebia por 40 horas, mais jornadas extraclasse, um salário de apenas três dígitos (791 reais), aproximadamente um terço do que era pago no Distrito Federal. Esses dados ficam mais incongruentes quando cotejados com os índices de desenvolvimento dos estados da Região Sul que, segundo o PNUD (em 2012), estavam entre os seis mais desenvolvidos do país: Santa Catarina com índice de 0,840 ocupa o $2^{\circ}$ lugar; Rio Grande do Sul, com 0,832, ocupava o $3^{\circ}$ lugar e Paraná, o 6o lugar, com 0,820. Em 1ํ lugar estava o Distrito Federal, com índice de 0,874 . 
Há que se considerar que as condições para conservar e atrair para o magistério professores de qualidade incluem a sua remuneração. A OCDE analisa a qualidade do percurso educativo/ formativo e profissional dos professores como indicador dos sistemas educacionais (NEVES, 2008, p. 87). Considerando o contexto da Região Sul do país, pergunta-se: como o trabalho do professor poderá gerar qualidade da educação, levando em conta suas condições profissionais, sua remuneração e suas possibilidades de educação continuada?

\section{A disciplina Arte no contexto da relação "arte, cultura e desenvolvimento"}

A disciplina Arte, no Brasil, talvez seja a que tem a mais peculiar trajetória de inserção na educação formal. Como forma de conhecimento, a arte é um das mais antigas da humanidade, mas isso não é garantia de sua valorização por parte da escola e da sociedade. Foi apenas na década de 70 que aconteceu a inclusão obrigatória no currículo escolar. Mas o foi como mera atividade, não como disciplina, como as demais. A chamada Educação Artística tinha natureza polivalente, que já vinha desde os cursos de formação de seus professores, que incluíam nos currículos disciplinas de Artes Cênicas e de Música. Durante muitos anos, a polivalência se disseminou na escola, com professores "atuando" nas várias linguagens da arte. Mas vieram reformas, nova LDB, novas concepções sobre arte e seu ensino, e é provável que hoje todas as licenciaturas alteraram sua denominação, de Educação Artística para Licenciatura em Artes Visuais, em Dança, em Música ou em Teatro. Mas como essa situação se apresenta na prática escolar, no currículo realmente em ação nas escolas?

No site Seja um professor, do MEC, há informações sobre o perfil do professor de Artes Visuais:

\footnotetext{
O Licenciado em Artes Visuais deve ser educado para a docência de Arte Artes Visuais - em todos os níveis do ensino formal e não-formal, incluindo a elaboração de materiais pedagógicos. Deve, também, desenvolver a produção, a pesquisa, a crítica e a mediação artístico-cultural nas modalidades de arte pública, cerâmica, desenho, fotografia, história em quadrinhos, ilustração, home page, vídeo, holografia, computação gráfica, escultura, gravura, mural, modelagem, grafite, land art, livro de artista, multimídia, instalação, objeto, performance, pintura, arte digital, teoria, história e crítica de artes visuais, entre outras (Em: $<$ http://sejaumprofessor.mec.gov.br>. Acesso em junho de 2012).
} 
O trecho evidencia a renúncia à polivalência. Da mesma forma o faz o Decreto que explicita a formação do professor da educação básica "no ensino de sua especialidade": O Parágrafo 4ํㅡㄹ do Artigo 3ํㅡㄹ do Decreto № 3.276/1999, que dispõe sobre a formação em nível superior de professores para atuar na educação básica, diz que "a formação de professores para a atuação em campos específicos do conhecimento far-se-á em cursos de licenciatura, podendo os habilitados atuar, no ensino da sua especialidade, em qualquer etapa da educação básica."

Está claro então que, oficialmente, a polivalência está extinta no nível da Lei. No campo da reflexão ela vem sendo combatida desde o início do Pós-Modernismo da arte-educação brasileira, que, segundo Barbosa, data do início da década de 80, com o Festival de Inverno de Campos de Jordão (1983). Nessa década, em 1987, foi criada a FAEB (Federação de Arte-educadores do Brasil), sendo que o $1^{\circ}$ Congresso Nacional aconteceu no ano seguinte. Desde a sua criação a FAEB condena a licenciatura curta para a formação do professor de Educação Artística e a polivalência. A primeira não existe mais, graças aos movimentos político-pedagógicos dos arteeducadores nos últimos 30 anos, mas a polivalência insiste em não sucumbir.

Atualmente, inúmeros concursos para provimento de cargos de professores de Arte estão sendo realizados no país. Mas o que tem chamado a atenção (e tem sido discuto em listas e grupos da internet, notadamente na lista da FAEB) é a crença na possibilidade de um professor habilitado em uma dada área ser efetivado para atuar em outra área. Isso tem sido encarado como uma tentativa de gestores da educação de legitimar novamente a ideia da polivalência. É provável que o objetivo primeiro seja o de cortar gastos com pessoal, mas é, acima de tudo, a disseminação de um equívoco dos órgãos gestores da educação básica.

Um depoimento em uma lista de discussão on line sobre arte-educação menciona que uma determinada Secretaria de Educação estaria contratando professores de Arte, dando preferência a:

[...] professores multifuncionais, ou seja, que saibam música, ensaiar coral, teatro de bonecos, encenar danças folclóricas, balé clássico, história da arte de todos os tempos, arte pós-moderna e contemporânea, arte do circo, lúdico infantil e se possível arte-terapia para acalmar os alunos (Em: $<$ faeb@yahoogrupos.com.br>. Acesso em maio de 2012). 
A leitura dessas palavras provoca risos e remete a uma impossibilidade, já que elas descrevem um professor fictício. Afora situações hilárias como essa, a realidade é que os professores de Arte se deparam frequentemente com tais exigências, tanto nos concursos, quanto no trabalho na escola, onde são intimados a atuar em várias linguagens da arte, como visuais, música, dança e teatro.

Talvez seja pertinente perguntar: de onde vem a ideia de polivalência? Como ela se apresenta na sociedade? Quem ou o quê divulga e legitima essa ideia? Como a disciplina poderá recuperar sua integridade no contexto mais amplo da sociedade?

\title{
Os cursos de formação de professores de Artes Visuais
}

Procurando informações em sites de cursos de formação de professores em Instituições de Ensino Superior (IES) sobre conteúdos desenvolvidos em cursos de Licenciatura em Artes Visuais, encontra-se, por exemplo:

\begin{abstract}
O Curso de Licenciatura em Artes Visuais contempla várias disciplinas na área das artes em geral: desenho, pintura, escultura, serigrafia, elementos gráficos (desenho virtual), audiovisual (cinema e vídeo), musicalização, coral, violão, flauta, técnica vocal, semiótica e sintaxe visual, teatro, história da arte, história da música, libras, psicologia da educação, gestão educacional, didática, materiais expressivos, arte educação, metodologias nas áreas das artes, prática de ensino e pesquisa científica (Em: <http://www.culturapa.com/2011/11>. Acesso em junho de 2012) (grifos adicionados).
\end{abstract}

Esse é apenas um exemplo dos equívocos envolvendo a polivalência, que vêm ocorrendo em diversas regiões do país. Algumas IES do Rio Grande do Sul, São Paulo, Rio de Janeiro, Amazonas, Sergipe e Distrito Federal mantêm disciplinas de Música e Teatro em seu currículo, contribuindo assim para a manutenção do equívoco. Entretanto, um ponto positivo é que a maioria dos cursos de formação de professores de Arte do país abandonou a formação polivalente, seguindo as recomendações do MEC.

No rastro da LDB 5692/71 os cursos de Licenciatura e Educação Artística eram "em sua grande maioria superficiais e genéricos, desarticulados epistemologicamente e centrados nas técnicas artísticas com finalidade para o uso escolar em atividades para crianças e jovens" (ARAÚJO, 2010, p. 80). Essa Educação Artística e o que ela trouxe em seu bojo contribuíram para a construção do pensamento sobre arte que está nas ruas, no senso comum e na própria escola. Não é preciso dizer que o 
conhecimento sobre arte e seu ensino produzido na Academia não é acessível à população em geral. Isso pode ser visto, por exemplo, no vídeo "Quem faz o quê?" produzido pela TV UFG ${ }^{8}$. Perguntadas sobre o papel do professor de Artes Visuais, as pessoas revelam concepções de cunho formalista ("ensina como trabalhar elementos visuais em produções"), tecnicistas ("ele ensina técnicas de pintura, de escultura...") ou confusas ("ele transmite a arte dele para o público"). Esses depoimentos ilustram um pensamento bastante disseminado. As antigas "belas artes" ainda estão no imaginário da população, alheio aos diferentes modos de pensar as linguagens presentes na arte contemporânea.

Uma pergunta cabe aqui: Qual é a dimensão do distanciamento entre as concepções sobre arte encontradas na Academia e as dos nossos alunos na escola? Tal distanciamento não seria diretamente proporcional ao existente entre a pósgraduação e a educação básica?

Para refletir sobre diferentes concepções sobre arte, apresento algumas respostas de alunos de escola pública às perguntas: O que é uma obra de arte? Você tem alguma obra de arte na sua casa? ${ }^{9}$

Da Educação Infantil até o 4ํano, obras de arte podem ser:

\begin{abstract}
Quadros (de Jesus, São Jorge e paisagens), vasos, animais de porcelana, bibelôs, guarda-roupa, lustre, aquário, tapete da sala, vaso com flores, livro com figuras coloridas, jardim, flores, desenhos feitos por eles, bons sentimentos, fotos de gente fazendo pose, fotografias [em geral, de alguém ou algo de que gostam], caixinhas enfeitadas, panos de prato pintados ou bordados, coisas de crochê, tricô ou bordado, coisas que foram feitas com as mãos, violão, objetos com materiais reciclados como garrafas PET ou rolinhos de jornal, bichos de pelúcia, enfeites de geladeira, louça pintada, bijuteria, sapatos, relógios, livros, móveis, música, velas, porta-retrato, chaveiro, corte e pintura de cabelo, sabonete pintado, flores de tecido, imã de geladeira, guardanapos e toalhas feitas à mão, cortina com miçangas, enfeites no jardim, tudo que é bonito de olhar...
\end{abstract}

Do 5ำ ano até o Ensino Médio, são consideradas obras de arte:

Novelas de TV, cerca de pedra, imã de geladeira, origami, quadro com paisagens, escultura de animais, azulejo de cozinha, imagem da Santa Ceia, imagem do Sagrado Coração de Jesus, relógio com pêndulo, coisas antigas, retrato antigo, relógio com o símbolo do Grêmio, crucifixo, quadros bem pintados, escultura em madeira, vaso egípcio, tapete decorado, móveis

\footnotetext{
8 Disponível em: <http://www.youtube.com/watch?v=XB6ifRIWY0s\&feature=relmfu>

9 Questões propostas em atividade da disciplina Seminário Integrador 3 do Curso de Licenciatura em Artes Visuais a distância em parceria UFRGS/UCS.
} 
decorados, bibelôs, esculturas de biscuit, crochê, bordados, vasos de barro, boneca antiga, pôster do Inter, paisagens bonitas, velas decoradas, lembranças de viagens, almofada bordada com lantejoulas, CD do Luan Santana, Hip Hop, Batidão Sertanejo, móveis, retratos feitos à mão, pátio, telefone celular, criação de ovelha, revista de bordados, uma parede com grafite, estátuas de santos, pintura abstrata na porta da sala, o sabor da comida, móbiles, açucareiro de vidro, latas pintadas, coleção de cartões de orelhão [telefone público], utensílios da casa, aparelho de som, computador, espelho, cadeira de praia, trabalhos manuais, "entre outras coisas".

Essas ideias revelam concepções sobre arte com as quais nós, pesquisadores da arte-educação, não pactuamos. Tais ideias foram construídas pelos estudantes em interações com o seu meio cultural. São ideias propagadas pelos pais, professores e pelas diversas mídias que têm acesso e que são apropriadas por eles. É como se um currículo oculto Ihes tivesse ensinado que arte tem a ver com beleza, que deve ser contemplada para deleite sensorial, mas não para ser interpretada; arte tem a ver com o belo e com o bom, com o que faz bem ao ser humano. É perceptível o distanciamento entre as concepções sobre arte encontradas na Academia e as dos nossos alunos. Em outras palavras, é perceptível o distanciamento entre o "nosso" capital cultural e o dos alunos.

$O$ distanciamento entre o que se pensa na Academia, seja em cursos de formação de professores, seja na pós-graduação, e a prática da disciplina Arte é apenas uma faceta do fenômeno. Apesar de a produção acadêmica ser de vanguarda, a prática docente em arte parece não ter sido contaminada por tais reflexões. No mundo acadêmico tem-se o pós-modernismo crítico, de resistência, problematizando conceitos, enquanto que na escola tem-se a preferência pela História da Arte hegemônica e a (so)negação do multiculturalismo. As pesquisas apontam métodos, abordagens e conteúdos visando à emancipação do sujeito, à conscientização, à desalienação, enquanto que no cotidiano da escola o marasmo prevalece. As exceções vão parar nos jornais e revistas especializadas; são premiadas e exibidas, mas o dia-a-dia é perpassado pela mediocridade. Estuda-se o desenho infantil, as abordagens contemporâneas de como trabalhar com o desenho na escola, mas na sala de aula a criança é impedida de construir a linguagem do desenho, porque impera a noção de que o desenho da criança é melhor do que o do adulto. Impera ainda um pensamento do início do século XX, do qual o excerto é um exemplo: "a criança pequena é mais perfeita do que a grande [...] é mais rica de símbolos, é mais autêntica, é mais feliz." [E] "geralmente, é mais original o desenho das primeiras idades quando 
menos se manifesta a influência da escolaridade" (MARINO, 1957, 136). Com a intenção de respeitar a criança, sonegamos-lhe a linguagem da arte, privando-a do acesso aos códigos da linguagem do desenho, da aprendizagem de uma das formas de expressão e comunicação humanas. A esse respeito Efland pergunta: "Por que as nossas práticas de ensino ainda estão baseadas em concepções modernistas de arte? Por que nós continuamos avaliando nossos alunos pela sua originalidade ou criatividade mais do que pela sua acuidade representacional ou algum outro critério?" (EFLAND, 1998, p. 12). A escola está repleta de ideias velhas sobre o papel da arte na educação, ideias com mais de cem anos que não servem para o contexto de hoje.

Conceitos, concepções, epistemologias presentes nos currículos formais de IES que oferecem cursos de Licenciaturas em Artes Visuais desvelam uma mudança de pensamento sobre como se dá o conhecimento da arte, a partir das contribuições de várias ciências imbricadas com a educação. No entanto os currículos em ação na escola não revelam coerência com tais concepções.

Talvez a pergunta pertinente aqui seja: os saberes e as práticas da disciplina Arte se cruzam com os da pesquisa na pós-graduação na área? E não seria a pósgraduação um elemento de fundamental importância na formação inicial do professor de Arte?

\section{A pós-graduação na Região Sul}

É irônico que a Região Sul do país, que tem os mais baixos pisos salariais para professores da educação básica, é a que mais forma professores habilitados em Artes Visuais em mais de 20 cursos de Licenciatura. E no nível da pós-graduação, a Região também é uma das que mais produzem pesquisas em mais de 30 cursos de pósgraduação em educação stricto sensu recomendados e reconhecidos. Apenas a Região Sudeste tem número maior, com mais de 60 cursos de educação stricto sensu. Além desses programas, existem outras opções de cursos que possibilitam o desenvolvimento de pesquisas ligadas à arte-educação, como é o caso do Mestrado Acadêmico em Processos e Manifestações Culturais da FEEVALE/RS e de novos Mestrados Profissionais. 


\section{A produção da pós-graduação no Rio Grande do Sul}

Nos últimos dez anos centenas de pesquisas têm abordado a arte-educação nos principais Programas de Pós-Graduação em Educação stricto sensu do Estado (UFRGS, UFSM, PUC/RS, UPF, UFPel).

Quanto à divulgação, alguns trabalhos resultantes da pesquisa no Programa de Pós-Graduação em Educação da UFRGS enfocando as relações das artes visuais com a educação foram divulgados em livros. O livro A Educação do Olhar no Ensino das Artes, organizado por Analice Dutra Pillar, cuja $1^{\text {a }}$ edição é de 1999 , teve a $7^{\text {a }}$ edição em 2012. Essa última foi produzida para atender o Projeto Sala de Leitura as Secretaria Estadual de Educação de São Paulo, com uma tiragem de 4.211 exemplares. O livro Imagens que Falam: Leitura da Arte na Escola, de Maria Helena Wagner Rossi, cuja $1^{\underline{a}}$ edição é de 2003, está na $5^{\mathrm{a}}$ edição e teve uma edição especial para compor o acervo do Plano Nacional da Biblioteca do Professor em 2011, com tiragem de 41 mil exemplares. Os livros Filosofia da Criação: Reflexões sobre o Sentido do Sensível, de Marly Meira, Criança e Pintura: Ação e Paixão do Conhecer, de Sandra Richter, Cor, som e movimento, organizado por Susana Rangel Vieira da Cunha, Crianças no computador desenvolvendo a expressão gráfica, de Lezi Fleischmann, já reeditados, vêm divulgando as pesquisas em arte-educação do PPGEDU da UFRGS. ${ }^{10}$

Além de livros, a produção da Pós-Graduação em Educação da UFRGS com ênfase nas Artes Visuais tem sido publicada em artigos, capítulos de livros ${ }^{11}$, bem como na Revista Educação \& Realidade da Faculdade de Educação da UFRGS. O volume 30, número 2, intitulado Dossiê Arte e Educação: arte, criação e aprendizagem, apresenta artigos do corpo docente e do discente.

A produção dos alunos e do corpo docente dos cursos de Mestrado e Doutorado em Educação da Linha de Pesquisa Educação e Artes da Universidade Federal de Santa Maria tem sido publicada na Revista Digital do LAV (Laboratório de Artes Visuais) do Centro de Educação da UFSM. Além disso, a revista, que é

\footnotetext{
${ }^{10}$ Os livros e revista aqui citados foram publicados pela Editora Mediação de Porto Alegre.

11 Um levantamento da produção bibliográfica de alunos e ex-alunos do Programa de Pós-Graduação em Educação da UFRGS identificou perto de uma centena de artigos abordando as artes visuais na educação, nos últimos dez anos.
} 
semestral, divulga trabalhos de autores oriundos de outros programas do país, bem como de iminentes autores do campo da arte-educação nacional e internacional.

No contexto nacional a pós-graduação em educação relacionada às artes visuais tem uma produção significativa que, nos limites deste texto, não é possível dimensionar. Há que se acrescentar nesse contexto a presença de Anais de diversos Congressos realizados no país, tais como o CONFAEB, o da ANPAP e o da ANPED. O CONFAEB (Congresso da Federação de Arte/educadores do Brasil) teve a 23a edição em 2013, sendo o maior evento da arte-educação brasileira, cujos Anais divulgam pesquisas inclusive resultantes de cursos stricto sensu. O Congresso Nacional da ANPAP (Associação Nacional de Pesquisadores em Artes Plásticas) gerou, nos últimos cinco anos, mais de 300 trabalhos no âmbito do Comitê Educação em Artes Visuais, que podem ser acessados pelo site da Associação. A Revista Brasileira de Educação, publicação quadrimestral da ANPEd, é também um meio de divulgação da produção da pós-graduação em educação no campo da arte-educação, além de outros periódicos nacionais.

\section{Perguntas finais}

Considerando o quadro que se desenha no país, com os salários degradados; as aviltantes condições para exercer o magistério; uma educação que não garante acesso pleno à cultura e que tem dificuldades para contribuir na formação de cidadãos; gestores da educação pública que desconsideram a educação, disseminando equívocos conceituais... Por outro lado, considerando que a produção acadêmica da pós-graduação no campo da arte-educação visual já não é modesta e que o corpo docente que atua na educação básica é constituído também de pósgraduados, então é pertinente formular-se algumas perguntas: A pesquisa desenvolvida na pós-graduação pode alimentar a educação básica, trazendo contribuições teórico-conceituais e metodológicas para a disciplina Arte? Em que medida os referenciais que fundamentam as pesquisas da pós-graduação estão interessados nos problemas da disciplina Arte? As discussões geradas pelas pesquisas nos cursos de pós-graduação consideram - ou deveriam considerar - as recomendações das organizações internacionais que avaliam a educação básica brasileira? Que efeitos tem a globalização da educação via avaliações internacionais no nosso sistema educacional? Como encontrar o equilíbrio entre atender às 
recomendações das organizações internacionais e pensar sobre o nosso contexto com autonomia?

Como apontado na introdução, este texto não tem a pretensão de apontar soluções para o problema do distanciamento entre a pós-graduação e a disciplina Arte na educação básica. Mas refletir, formulando perguntas, talvez seja um meio de tentar novos olhares para "ver o que ainda não vimos" nesse contexto.

\section{Referências}

ARAÚJO, Alcione. Entrevista. Programa Sintonia. TV Cultura. 2007. Disponível em: $<\mathrm{http}: / /$ www.youtube.com/watch?v=CdbAUu7Ptn0\&feature=related $>$. Acesso em 26 de fevereiro de 2012.

ARAÚJO, Anna Rita Ferreira de. Os cursos superiores de formação de professores de artes visuais no Brasil: percursos históricos e desigualdades geográficas. In: 32ª Reunião Anual da ANPEd, 2010. Anais... Disponível em: <http://www.anped.org.br/reunioes/32ra/arquivos/trabalhos/GT24-5360-Int.pdf>. Acesso em 3 de março de 2012.

BARBOSA, Ana Mae. A imagem no ensino da arte. São Paulo: Perspectiva, 1991.

BOURDIEU, Pierre. A economia das trocas simbólicas. São Paulo: Perspectiva, 1982.

BRASIL. Ministério da Educação. PDE: Plano de Desenvolvimento da Educação: SAEB: ensino médio: matrizes de referência, tópicos e descritores. Brasília: MEC, SEB; Inep, 2008.

EFLAND, Arthur. Cultura, sociedade, arte e educação em um mundo pós-moderno. In: A COMPREENSÃO E O PRAZER DA ARTE, 1998. Anais... São Paulo: SESC, 1998.

FELLET, João. Brasil avança no ranking do IDH, mas alta desigualdade persiste. Jornal BBC Brasil. Disponível em <http://www.bbc.co.uk/portuguese/noticias/2011/11/111102_brasil_idh_jf.shtml> Acesso em 26 de fevereiro de 2012.

FERREIRA, João Luis Silva. Entrevista. Folha de São Paulo/ llustrada. 22 de março de 2012. Disponível em: <http://www1.folha.uol.com.br/ilustrada/1065045-gestao-de-ana-de-hollanda-e-desastre-afirmaex-ministro-da-cultura.shtml> Acesso em 23 de março de 2012.

FLEURI, Reinaldo Matias. Entre o oficial e o alternativo em propostas curriculares: para além do hibridismo. Revista Brasileira de Educação [online]. 2001, n.17. Disponível em: <http://www.scielo. br/pdf/rbedu/n17/n17a08.pdf.> Acesso em 23 de março de 2012.

MARINO, Divo. O desenho da criança. São Paulo: Editora do Brasil S.A., 1957.

NEVES, Claudia Susana Coelho. As organizações internacionais e a avaliação dos sistemas de educação e formação: análise crítica e comparativa. Revista Europeia de Formação Profissional. N. 45. Mar 2008. Disponível em: <http://www.cedefop.europa.eu/etv/Upload/Information_resources/ Bookshop/533/45_pt_Neves.pdf> Acesso em 11 de março de 2012.

OCDE. Avaliação da gestão de recursos humanos no governo: Relatório da OCDE - Brasil 2010. Disponível em: <http://books.google.com.br/books?id=ykvk12XFYelC> Acesso em 26 de fevereiro de 2012.

OECD [OCDE] Multilingual Summaries. Equidade e Qualidade na Educação: apoio às escolas e aos alunos desfavorecidos. Paris, 2012. Disponível em <http://www.oecd.org/dataoecd/4/ 32/49620070.pdf> Acesso em 26 de fevereiro de 2012.

POCHMANN, Marcio. Entrevista. Revista Visão Classista. N. 9, mar, 2012. p. 9-14. Disponível em: $<$ http://portalctb.org.br/site/publicacoes/revistas> Acesso em 11 de março de 2012. 


\section{Maria Helena Wagner Rossi}

Cursou Licenciatura em Desenho e Plástica, Mestrado e Doutorado em Educação na UFRGS. É professora de Arte aposentada da rede estadual de ensino do RS. Desde o início da década de oitenta é professora/pesquisadora na Universidade de Caxias do Sul (UCS) nos cursos: Artes Visuais, Pedagogia e Psicologia. É líder do Grupo Interdisciplinar Arte, Cultura e Patrimônio - CNPq/UCS e vice-líder do Grupo de Pesquisa em Educação em Arte (GEARTE) - CNPq/PPGEDU/UFRGS. Tem publicado artigos em revistas e capítulos de livros sobre leitura de imagens e compreensão estética visual. É autora do livro Imagens que falam: leitura da arte na escola, publicado pela Editora Mediação (5ª edição: 2011; PNBE: 2011).

E-mail - mhwrossi@gmail.com

Curriculo - http://lattes.cnpq.br/5017888754814808 